\title{
Study on Mechanical Properties of Flexible Base Asphalt Pavement in Permafrost Regions
}

\author{
Yingying $\mathrm{Li}^{1, \mathrm{a},{ }^{*}}$, Xuesong Mao, ${ }^{1, \mathrm{~b}}$, Baolong Zhang ${ }^{1, \mathrm{c}}$ \\ ${ }^{1}$ Chang'an University Xi'an, 710064 Shannxi, China \\ a2411789692@qq.com, bxuesongmao@yahoo.com.cn
}

\begin{abstract}
Keywords: Permafrost regions, Mechanics characteristics of pavement structural, Numerical
\end{abstract} simulation, Displacement deformation, Maximum principal stress

\begin{abstract}
In order to study the adaptability of reasonable pavement structure in permafrost regions, the first-stage construction of Gonghe-Yushu highway from K629 + 800 K634 + 200 is taken as test section, and establishes the numerical simulation model of subgrade and pavement by using Flac3D software. Compares and analyzes the mechanical properties with semi-rigid base asphalt pavement and flexible base asphalt pavement structure. In the end, recommends a reasonable pavement structure type in permafrost regions: flexible base asphalt pavement structure. The results show that: in the long term, the deformation range of flexible pavement structure is less than the semi-rigid base pavement structure. Therefore, the permafrost region pavement structure should give priority to the flexible base asphalt pavement structure.
\end{abstract}

\section{Introduction}

Due to the special climate and geological environment, the diseases of frost heaving and thawing subsidence are serious ${ }^{[1]}$. In this end, many scholars at home and abroad to carried out a number of studies. Through the research of highway in Shanxi Province, Li Shihua ${ }^{[2]}$ found that most of the highway is semi-rigid base asphalt pavement structure. But, along with the increasing traffic, many disasters take place, such as rut and transverse cracks, which seriously influence the development of the economy. Zhou Yanqing ${ }^{[3]}$ shows that the flexible base has stronger resistance ability to vertical deformation. From above analyses, we can know that: the semi-rigid base asphalt pavement of high-grade pavement structure has many defects in the permafrost regions, but the flexible base asphalt pavement structure is more reasonable. However, the flexible base asphalt pavement is mainly used for the foreign highways, research on the highway especially the high grade highway in China is less. Based on existing researches, this paper takes Gonghe-Yushu highway from K629 + $800 \sim \mathrm{K} 634+200$ as the test road. And uses Flac3D software to set up the numerical simulation model of subgrade and pavement structure which compares and analyzes the mechanical properties of the semi-rigid base asphalt pavement and flexible base asphalt pavement structure.

\section{Numerical simulation of subgrade and pavement structure}

\subsection{Establishment of numerical model}

The calculation model structure are shown in figure 1.

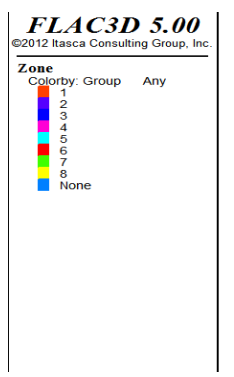

Figure 1. Numerical model of subgrade and pavement structure 


\subsection{Determination of boundary conditions}

(1) Displacement boundary conditions: the constraint is applied in the $\mathrm{x}$ and $\mathrm{y}$ directions on the left and right sides of the model, and only the model can be shifted in the $\mathrm{z}$ direction. (2) Water boundary conditions: the asphalt concrete surface is treated as an impermeable interface. The optimum moisture content of subgrade construction is 14\%. (3) External load boundary conditions: it uses the most unfavourable condition of loading when calculates

\section{Analysis of mechanical properties of pavement structure}

\subsection{Analysis of calculation results of deformation fields}

Through our investigation and analysis, July was identified as the worst month. By means of numerical simulation, the pavement structure performance of semi-rigid base pavement structure and flexible base pavement structure is simulated in the most adverse month of 1,5 and 10 years later.

(1) The displacement of semi-rigid base pavement structure

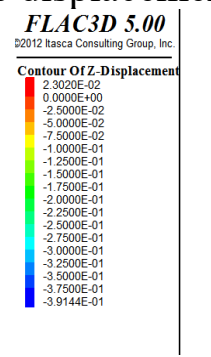

a) The displacement of semi-rigid in the year 1

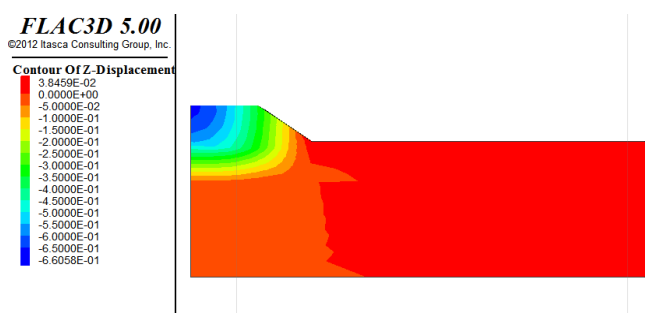

(b) The displacement of semi-rigid in the 5 th year

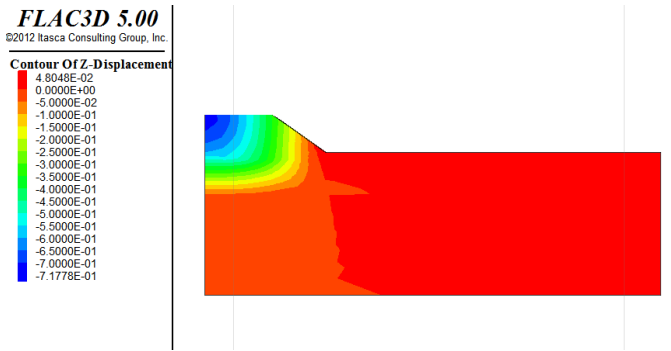

(c) The displacement of semi-rigid in the 10th year

Figure 2. The displacement of semi-rigid base pavement structure

(2) The displacement of flexible base pavement structure

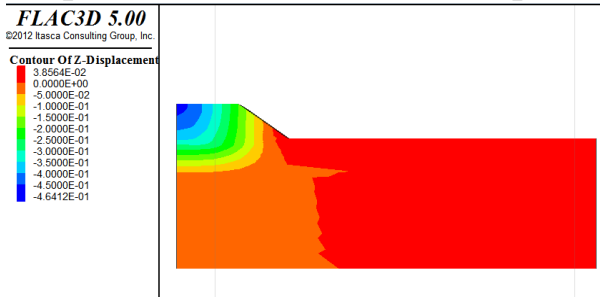

(a) The displacement of flexible in the year

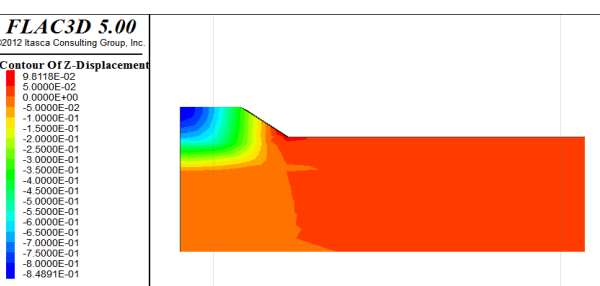

(b) The displacement of flexible in the 5 th year
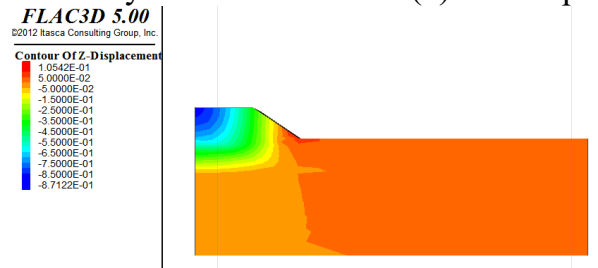

(c) The displacement of flexible in the 10th year

Figure 3. The displacement of flexible base pavement structure 
It can be seen from the above cloud chart that the surface layer of the whole structure is subsiding, and the overall subsidence deformation of the road structure also causes upward deformation at the foot of the subgrade. It is found that the subsidence of the pavement center is the largest. With the increase of road distance, the surface subsidence gradually decreases and the difference between the settlement of the middle and that of the edge can reach $26.8 \mathrm{~cm}$. Through the observation of the test road subsidence, it is found that the maximum subsidence of the first year is $65.2 \mathrm{~cm}$, which is consistent with the simulation results. Combining with the field investigation on the highway in Qinghai-tibet region, it can be seen that due to the seasonal melting of permafrost, the soil base bearing capacity decreases, causing uneven subsidence of pavement structure, which is one of the main types of pavement diseases in this region.

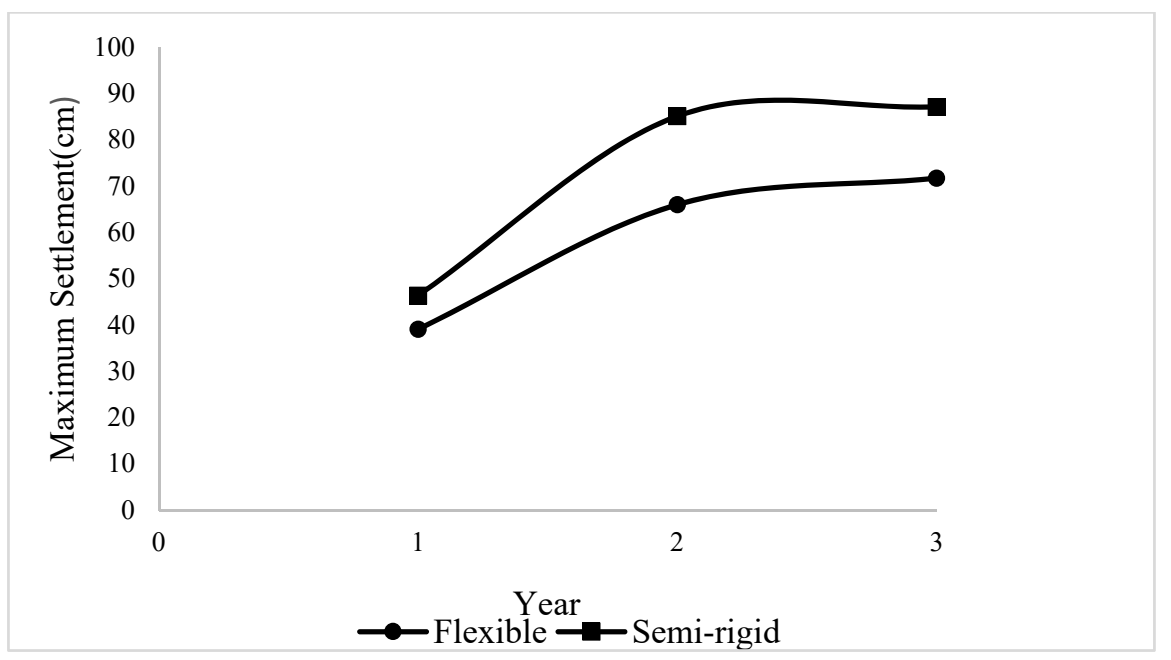

Figure 4. The surface settlement deformation of different structures

The subsidence deformation of different pavement structures in the 1st, 5th and 10th years (Figure 4) shows that: under the same conditions of thawing settlement of permafrost and vehicle load, the semi-rigid base pavement structure is cement stabilizing crushed rock and platebody structure with a large bearing capacity, and the real implications of the cracks in the model cannot be considered. Thus, under the same load, its subsidence deformation is minimal. The basic structure of flexible base pavement is composed of ATB-25 and graded crushed rock, and the basic structure is flexible. Therefore, the deformation under the same load is the largest, which is higher than the semi-rigid base pavement structure. However, further analysis found that the durability of graded crushed stone material is significantly better than that of cement stabilized crushed rock, and its material forming condition is low, and the mechanical properties of materials are reduced over time. So we can see that, with time going by, the deformation of flexible base asphalt pavement structure gradually stabilized, and the subsidence rate is only $2.3 \%$ compared with the flexible base asphalt pavement structure in 10th years and 5th years, while the growth rate of semi-rigid base pavement structure is $8 \%$ at the same time. Therefore, the stability of flexible pavement structure is better in the long run.

\section{Conclusion}

1) By using Flac3D software, the whole model of the first-stage construction of Gonghe-Yushu highway from K629 $+800 \sim \mathrm{K} 634+200$ and production road was set up. According to the investigation of the diseases, the pavement structure behavior of the permafrost regions was evaluated from one aspects: vertical displacement

2) According to the quantitative comparative analysis of structural sample data of subgrade and pavement, the flexible base pavement material durability is better, the material performance decay is small. And the deformation degree in the 10th year is smaller than that of in the 5th year. The resistance to deformation ability of flexible base asphalt pavement structure stability is better than the semi-rigid base pavement structure in the long term. 
3) On the whole, the pavement structure of the flexible base pavement is better than the semi-rigid base pavement structure, which proves the rationality of the pavement structure.

\section{Acknowledgement}

This research was financially supported by the Special Found for Basic Scientific Research of Central College of Chang'an University (300102218408) and China Railway First Research Project 2016A-061.

\section{References}

[1] Wang Shuangjie, Wang Zuo, Yuan Kun. Review and prospect of highway engineering geology in the permafrost region of qinghai-tibet highway [J]. Journal of China Highway, 2015, 28(12): $1-8$.

[2] Li Shihua, Wang Xiushan. Mechanical response analysis of semi-rigid asphalt pavement under dynamic load [J]. Chinese and foreign highways, 2016, 36(05):49-53.

[3] Zhou Yanqing. Semi-rigid base asphalt pavement - subgrade coordination design [J].Journal of Shandong Jiaotong university, 2016, 24(02):66-70.

[4] Zubeck H K, Dore g. Introduction to Cold Regions Pavement Engineering [J]. a) American Society of Civil Engineers, 2009. 